\title{
SOFRIMENTO MORAL VIVENCIADO NA PRÁTICA DA EQUIPE DE ENFERMAGEM DE CENTRO CIRÚRGICO
}

\author{
Vanessa Torres Pereira ${ }^{1}$; Marluce Alves Nunes Oliveira ${ }^{2}$ \\ 1. Bolsista PIBIC/FAPESB, Graduando em Enfermagem, Universidade Estadual de Feira de Santana, \\ e-mail:fsavtp@hotmail.com \\ 2. Orientador, Departamento de Saúde, Universidade Estadual de Feira de Santana, e-mail: milicialves@yahoo.com.br
}

PAlAVRAS-CHAVE: Equipe de Enfermagem; Centro Cirúrgico; Sofrimento Moral.

\section{INTRODUÇÃO}

O sofrimento moral decorre de situações em que o profissional se sente pressionado a agir de uma forma eticamente, como exemplo, omissão aos familiares sobre os erros cirúrgicos, que são frequentes no contexto de centro cirúrgico (CC). O CC é uma "unidade destinada ao desenvolvimento de atividades cirúrgicas, bem como à recuperação pósanestésica e pós-operatória imediata" (BRASIL, 2002, p. 160). Os procedimentos cirúrgicos são desenvolvidos por uma equipe multiprofissional integrada e habilitada. Para Oliveira e Santa Rosa (2015), por ser um ambiente complexo, os profissionais que atuam neste setor estão susceptíveis a situações conflituosas que envolvam aspectos éticos e morais.

Para Dalmolin (2012), o sofrimento moral pode ser entendido como sentimentos dolorosos e de desequilíbrio psicológico, que surgem quando os profissionais têm conhecimento sobre o comportamento moralmente correto, porém ocorrem obstáculos que os impedem de conduzir essa ação, esses obstáculos podem ser a falta de tempo, inibidora atitude do poder médico, ordem jurídica, dentre outros.

Cotidianamente os profissionais de saúde, em suas relações de trabalho, estão susceptíveis ao sofrimento moral. Essas relações tornam-se desafiadoras, pois muitas vezes são caracterizadas por pessoas de diferentes formações, atitudes, qualidades e valores. Desse modo, cabe aos profissionais de saúde, em especial o enfermeiro de $\mathrm{CC}$, a todo o momento, rever os valores éticos e morais, a fim de obter o equilíbrio na tomada de decisões frente às situações éticas.

Assim, este estudo tem como objetivo geral conhecer as situações de sofrimento moral vivenciado na prática da equipe de enfermagem de centro cirúrgico e como objetivos específicos analisar as situações de sofrimento moral vivenciados na prática da equipe de enfermagem no Centro cirúrgico, identificar a ação da equipe de enfermagem frente às situações de sofrimento moral vivenciados na prática de centro cirúrgico e estabelecer estratégias para o enfrentamento de sofrimento moral no centro cirúrgico.

\section{METODOLOGIA}

Para Minayo (2011, p.14), a metodologia consiste no "caminho do pensamento e prática exercida na abordagem da realidade". A autora ressalta a importância das teorias, métodos e técnicas, bem como a criatividade e experiência do pesquisador como atributos indispensáveis para a investigação (MINAYO, 2010).

Trata-se de um estudo qualitativo, exploratório - descritivo. Tendo como objeto de estudo o sofrimento moral vivenciado pela equipe de enfermagem de CC.

$\mathrm{O}$ estudo foi desenvolvido na unidade de Centro Cirúrgico de um hospital geral público de grande porte, localizado no município de Feira de Santana-BA-Brasil. Os participantes da pesquisa foram 08 profissionais da equipe de enfermagem que atuam no centro cirúrgico com mais de um ano e em atividade laboral no período da pesquisa. 
As informações foram coletadas nos meses de novembro e dezembro de 2016, por meio de entrevista semiestruturada, que continham as seguintes questões norteadoras: o que você entende por sofrimento moral? ; Fale-me de uma experiência de sofrimento moral vivenciada em sua prática de Centro Cirúrgico. Qual a sua ação frente sofrimento moral em sua prática de Centro Cirúrgico? Que estratégias podem ser utilizadas para a prevenção de situações de sofrimento moral no Centro Cirúrgico?

Os dados empíricos foram analisados a partir do método de análise de conteúdo de Bardin (2011). A análise de conteúdo "compreende técnicas de pesquisa que permitem, de forma sistemática, a descrição das mensagens e das atitudes atreladas ao contexto da enunciação, bem como as inferências sobre os dados coletados" (CAVALCANTE; CALIXTO; PINHEIRO, 2014, p. 14).

Ao realizar a análise dos relatos emergiram quatro categorias: "Entendimento da equipe de enfermagem sobre Sofrimento Moral", "Vivencia de sofrimento moral pala equipe de enfermagem no contexto de Centro Cirúrgico", "O fazer e o agir da equipe de enfermagem diante do sofrimento moral" e "Estratégias de prevenção do Sofrimento Moral".

Este projeto de pesquisa está inserido no projeto VIVÊNCIAS DE CONFLITOS E DILEMAS ÉTICOS NA PERCEPÇÃO DA EQUIPE ENFERMAGEM NO CENTRO CIRÚRGICO. O projeto foi submetido ao Comitê de Ética em Pesquisa da Universidade Estadual de Feira de Santana, sob CAAE no 28656214.9.0000.0053.

Durante o desenvolvimento da pesquisa foram considerados os aspectos éticos que envolvem pesquisas com seres humanos, estabelecidos pela Resolução $\mathrm{n}^{\circ} 466$ de 12 de dezembro de 2012, do Conselho Nacional de Saúde (CNS).

Dos 08 profissionais da equipe de enfermagem que participaram da pesquisa, 03 eram enfermeiros e 05 Técnicos de enfermagem. Todas do sexo feminino, a funcionária com maior tempo de atuação no $\mathrm{CC}$ tem 08 anos e a mais recentemente possui um ano. Em relação ao tempo de conclusão do curso de formação profissional, a mais antiga possui 14 anos de formação e a mais recente dois anos e dois meses. Quanto ao vínculo empregatício, seis possuem outros vínculos.

Da análise dos relatos dos profissionais da equipe de enfermagem emergiram as seguintes categorias (Tabela 1):

Tabela1. Categorias e subcategorias que emergiram dos relatos. Feira de Santana, 2017.

\begin{tabular}{|l|l|}
\hline CATEGORIAS & SUBCATEGORIAS \\
\hline $\begin{array}{l}\text { 1. Entendimento da equipe de enfermagem sobre } \\
\text { Sofrimento Moral }\end{array}$ & $\begin{array}{l}\text { Não agir de acordo aos princípios éticos - } \\
\text { morais; }\end{array}$ \\
& $\begin{array}{l}\text { Desrespeito ao profissional no contexto de } \\
\text { centro cirúrgico. }\end{array}$ \\
\hline $\begin{array}{l}\text { 2. Vivência de sofrimento moral pela equipe de } \\
\text { enfermagem }\end{array}$ & $\begin{array}{l}\text { Escassez de recursos materiais e espaço físico } \\
\text { restrito; }\end{array}$ \\
\hline $\begin{array}{l}\text { 3. O fazer e o agir da equipe de enfermagem diante } \\
\text { do sofrimento moral }\end{array}$ & $\begin{array}{l}\text { Ações que demonstram negligência, } \\
\text { imprudência e imperícia. }\end{array}$ \\
\hline 4. Estratégias para prevenção de Sofrimento Moral & $\begin{array}{l}\text { Comunicação/esclarecimentos ao familiar; } \\
\text { - Agir ético-moral }\end{array}$ \\
& $\begin{array}{l}\text { Promoção do diálogo com a equipe cirúrgica } \\
\text { planejamento para promoção de assistência } \\
\text { perioperatória de qualidade }\end{array}$ \\
\hline
\end{tabular}




\section{CATEGORIA I - ENTENDIMENTO DA EQUIPE DE ENFERMAGEM SOBRE SOFRIMENTO MORAL}

Os depoimentos das participantes do estudo revelam que o sofrimento moral é entendido como uma forma de agir desrespeitando a ética e a moral em relação ao pessoal/profissional.

\section{CATEGORIA II- VIVÊNCIA DE SOFRIMENTO MORAL PELA EQUIPE DE ENFERMAGEM}

Nesta categoria, os participantes mostram as suas experiências relacionadas com o sofrimento moral envolvendo a falta de recursos materiais e de infração ética.

\section{CATEGORIA III - O FAZER E O AGIR DA EQUIPE DE ENFERMAGEM DIANTE DO SOFRIMENTO MORAL}

Para as participantes, suas ações diante do sofrimento moral devem ser pautadas em comunicar/esclarecer os familiares quando estes estiverem envolvidos e em determinadas situações os profissionais preferem silenciar.

\section{CATEgoria IV - ESTRATÉgiAs PARA PREVENÇÃo DE SOFRIMENTO MORAL}

Os participantes em seus relatos colocaram como estratégias fundamentais para prevenção do sofrimento moral: ação observando os princípios éticos -morais; a promoção do diálogo com a equipe cirúrgica e o planejamento para promoção de assistência perioperatória de qualidade.

\section{CONSIDERAÇÕES FINAIS}

Esta investigação possibilitou conhecer as situações de sofrimento moral vivenciadas na prática da equipe de enfermagem de centro cirúrgico e que deve ser solucionado observando os preceitos éticos e legais da enfermagem.

Os participantes demostram entender o significado do sofrimento como forma de agir desrespeitando a ética e a moral, em relação ao pessoal/profissional.

$\mathrm{O}$ estudo apontou que a vivência dos participantes relacionadas com o sofrimento moral envolvem situações como a falta de recursos materiais, espaço físico limitado e ações que demonstram negligência, imprudência e imperícia.

As ações diante ao sofrimento moral devem ser pautadas em comunicar/esclarecer os familiares quando estiverem envolvidos em situações de sofrimento moral e silenciar.

Em relação às estratégias para prevenção do sofrimento moral o estudo apontou o agir ético-moral; a promoção do diálogo com a equipe cirúrgica e o planejamento para promoção de assistência perioperatória de qualidade.

A equipe de enfermagem vivencia sofrimento moral no $\mathrm{CC}$, portanto deve buscar fortalecer o relacionamento interpessoal dos profissionais, a fim de promover respeito no ambiente laboral, viabilizar ações educativas para fortalecer o exercício ético, precaução para evitar infração ética na prática, promover esclarecimentos aos familiares no intuito de minimizar os desconfortos e o sofrimento moral da equipe de enfermagem.

Entendemos que os profissionais da equipe cirúrgica devem atuar observando os princípios éticos e legas da profissão, busquem o diálogo no ambiente de trabalho e planejem a assistência perioperatória com qualidade, a fim de prevenir ocorrências de sofrimento moral.

As facilidades encontradas para realização deste estudo consistiram no acesso a infraestrutura do Núcleo Interdisciplinar de Pesquisas e Estudos em Saúde (NIPES). As 
dificuldades incidiram na deficiência de artigos científicos sobre o tema, a rotina da equipe de enfermagem no centro cirúrgico que dificultou a realização das entrevistas.

A partir destes achados, outros estudos sobre esta temática devem ser realizados e divulgados, a fim de que a equipe de enfermagem reflita sobre as situações de sofrimento moral vivenciada no $\mathrm{CC}$ e saiba tomar decisões pautadas nos princípios éticos e legais da profissão.

\section{REFERÊNCIAS}

BARDIN, L. Análise de conteúdo. 2011. 70. Ed., São Paulo: Almedina Brasil, p. 279.

BRASIL. Ministério da Saúde. Agência Nacional de Vigilância Sanitária. . 2002. RDC n50, de 21 de fevereiro de 2002. Dispõe sobre o Regulamento Técnico destinado ao planejamento, programação, elaboração, avaliação e aprovação de projetos físicos de estabelecimentos assistenciais de saúde. Diário Oficial da União, Poder Executivo, Brasília, DF.

CAVALCANTE, R. B.; CALIXTO, P.; PINHEIRO, M. M. K. 2014. Análise de conteúdo: considerações gerais, relações com a pergunta de pesquisa, possibilidades e limitações do método. Inf. \& Soc.: João Pessoa, v.24, n.1, p. 13-18, jan./abr.

DALMOLIN, G. L., et. al. 2012. Implicações do sofrimento moral para os(as) enfermeiros(as) e aproximações com o burnout. Texto contexto enferm. Florianópolis, v. 21, n. 1, p. 200-208, jan - mar.

OLIVEIRA, M. A. N., SANTA ROSA, D. O. 2015. Conflitos e dilemas éticos vivenciados pelo enfermeiro no cuidado perioperatório. cienc cuid saúde. v. 14, n.2, p. 1156 - 1163.

MINAYO, M. C. S. 2010.O desafio do conhecimento: pesquisa qualitativa em saúde. 12. ed. São Paulo: Hucitec, p. 407.

MINAYO, M. C. S. 2011. Pesquisa social: teoria, método e criatividade. 30. ed. Petrópolis, RJ: Vozes, p. 108. 